\title{
Diffusion of volatile organics through porous snow: impact of surface adsorption and grain boundaries
}

\author{
T. Bartels-Rausch ${ }^{1}$, S. N. Wren ${ }^{2}$, S. Schreiber ${ }^{1}$, F. Riche ${ }^{3}$, M. Schneebeli ${ }^{1}$, and M. Ammann ${ }^{1}$ \\ ${ }^{1}$ Paul Scherrer Institute, Laboratory of Radio- and Environmental Chemistry, 5232 Villigen PSI, Switzerland \\ ${ }^{2}$ University of Toronto, Department of Chemistry, Toronto, Ontario M5S 3H6, Canada \\ ${ }^{3}$ WSL Institute for Snow and Avalanche Research SLF, 7260 Davos Dorf, Switzerland
}

Correspondence to: T. Bartels-Rausch (thorsten.bartels-rausch@psi.ch)

Received: 1 February 2013 - Published in Atmos. Chem. Phys. Discuss.: 7 March 2013

Revised: 17 May 2013 - Accepted: 22 May 2013 - Published: 18 July 2013

\begin{abstract}
Release of trace gases from surface snow on earth drives atmospheric chemistry, especially in the polar regions.

The gas-phase diffusion of methanol and of acetone through the interstitial air of snow was investigated in a wellcontrolled laboratory study in the temperature range of 223 to $263 \mathrm{~K}$. The aim of this study was to evaluate how the structure of the snowpack, the interaction of the trace gases with the snow surface, and the grain boundaries influence the diffusion on timescales up to $1 \mathrm{~h}$. The diffusive loss of these two volatile organics into packed snow samples was measured using a chemical ionization mass spectrometer. The structure of the snow was analysed by means of X-ray-computed microtomography.

The observed diffusion profiles could be well described based on gas-phase diffusion and the known structure of the snow sample at temperatures $\geq 253 \mathrm{~K}$. At colder temperatures, surface interactions start to dominate the diffusive transport. Parameterizing these interactions in terms of adsorption to the solid ice surface, i.e. using temperaturedependent air-ice partitioning coefficients, better described the observed diffusion profiles than the use of air-liquid partitioning coefficients.

No changes in the diffusive fluxes were observed by increasing the number of grain boundaries in the snow sample by a factor of 7 , indicating that for these volatile organic trace gases, uptake into grain boundaries does not play a role on the timescale of diffusion through porous surface snow. For this, a snow sample with an artificially high amount of ice grains was produced and the grain boundary surface measured using thin sections.
\end{abstract}

In conclusion, we have shown that the diffusivity can be predicted when the structure of the snowpack and the partitioning of the trace gas to solid ice is known.

\section{Introduction}

\subsection{Environmental relevance}

Snow cover on the earth's surface is of significant environmental importance (Bartels-Rausch et al., 2012a). For example, the Arctic surface snow can hold a high concentration of volatile organic molecules (Shepson and Sumner, 1999). Snow also covers large parts of the Northern Hemisphere in winter, and high concentrations of volatile organics have been found in such surface snows (Kos and Ariya, 2010). Both in the Arctic, where volatile organics in snow are investigated as photochemical products, and in non-polar regions, where volatile organics mostly originate from biological soil emission (Groffman et al., 2001; Swanson, 2005) or from polluted air masses (Kos and Ariya, 2010), the fluxes between the snow and the air might impact air quality and climate change (Domine and Shepson, 2002; Grannas et al., 2007; Seok et al., 2009).

At low-wind conditions, fluxes between the porous surface snow and the overlaying atmosphere are driven by diffusion through the interstitial air (Domine et al., 2008). Diffusion describes the transport of gases in a single-phase system driven by a concentration gradient, and its rate is given by the diffusion coefficient or diffusivity. In porous materials, such as surface snow, diffusive transport through the open space 
(i.e. gas phase) is generally described by an effective diffusivity in the two-phase sample (Schwarzenbach et al., 2003). In Eq. (1), the effective diffusivity ( $D_{\text {eff }}$ ) is described by the gas-phase diffusion coefficient $\left(D_{\text {air }}\right)$, the free volume in the porous material (porosity, $\rho$ ), and the microscopic shape of the pores (tortuosity, $\tau$ ). For trace gases that interact with the surface of the porous material by surface adsorption, the gassolid partitioning coefficient $\left(K_{i}\right)$, the ice/air volume ratio $\left(r_{\mathrm{sp}}\right)$, and the specific surface area (SSA) are additionally included in the parameterization of $D_{\text {eff }}$ (Schwarzenbach et al., 2003; Herbert et al., 2006a; Domine et al., 2008). The effective diffusivity of any gas can thus be calculated based on known gas-phase diffusivity, microstructure of the porous medium and sorption characteristics.

$D_{\text {eff }}=D_{\text {air }} \times \frac{\phi}{\tau} \times \frac{1}{1+r_{\mathrm{sp}} \times K_{i} \times \mathrm{SSA}}$

In polar and subalpine snow or firn, the above correlation between the structure and the effective diffusivity has been empirically confirmed for non-surface interacting gases such as $\mathrm{CO}_{2}, \mathrm{CH}_{4}, \mathrm{O}_{2}$, and $\mathrm{SF}_{6}$ (Schwander et al., 1993; Fabre et al., 2000; Seok et al., 2009). Going one step further, Pinzer et al. (2010) have recently carefully verified the structurediffusivity relationship for NO by bringing together precise structural information gained from X-ray-computed tomography with observed effective diffusivities in well-defined laboratory experiments.

\subsection{Diffusion and surface interaction}

Pinzer et al. (2010) have further confirmed that species that interact strongly with ice surfaces, such as HONO (Chu et al., 2000; Bartels-Rausch et al., 2002; Kerbrat et al., 2010), exhibit a much lower effective diffusivity. The effective diffusivity at temperatures of 250 to $270 \mathrm{~K}$ is $2-3$ orders of magnitude smaller for HONO compared to non-interacting gases such as $\mathrm{NO}$ and $\mathrm{NO}_{2}$. The authors found that the lower effective diffusivity could be directly linked to HONO's strong air-ice partitioning. In particular, the air-ice partitioning coefficient determined based on the diffusivity agreed within experimental uncertainties with the Langmuir partitioning coefficient. The Langmuir model treats the partitioning as adsorption to solid ice surfaces (Crowley et al., 2010).

\subsubsection{Wet snow}

The finding of slow gas transport of interacting gases in snow is in agreement with a number of earlier field observations on the diffusion of $\mathrm{SO}_{2}$ (Choi et al., 2000), volatile(Helmig et al., 2009), and semi-volatile organics (Herbert et al., 2006a,b). For example, Herbert et al. (2006a) found that the effective diffusion of semi-volatile organics scaled with their tendency to stick to snow surfaces. However, in these field studies temperatures approached (and even exceeded) the melting point of ice, and consequently the snow held liquid water. Even the presence of a small fraction of liquid in wet snow can significantly modify the trace gassnow interaction, as both adsorption to the solid ice surface and dissolution into the liquid fraction might occur simultaneously (Choi et al., 2000; Bartels-Rausch et al., 2012b). Consequently, it was found that using the air-ice partitioning coefficient to model transport of semi-volatile organics in snow largely underestimated the diffusivities, questioning the application of these gas-solid partitioning data to derive the effective diffusivity for such wet snows (Herbert et al., 2006a,b). The authors suggest that the air-water partitioning might dominate the interaction and that the gas-liquid partitioning coefficient (i.e. Henry's law coefficients) might be better suited to describe diffusion in snow at temperatures close to the melting point. However, no direct measurement of the effective diffusivity was made in these studies, so the validity of using Henry's law coefficients has yet to be determined.

\subsubsection{Dry snow}

Herbert et al. (2006a,b) further suggested that the gas-liquid partitioning coefficient might be of importance for the interaction of trace gases with snow even at colder temperatures and in the absence of liquid. This idea is often motivated by the air-ice interface being disordered at a molecular level at temperatures approaching the melting point (Thomas et al., 2011; Bartels-Rausch et al., 2012b). The temperature dependence and thickness of this disordered layer, often referred to as quasi-liquid layer, has been investigated by a number of different techniques (Li and Somorjai, 2007). While a conclusive temperature-depth relationship can still not be given, the studies agree that the thickness of the disorder increases with temperatures approaching the melting point and reaches significant thicknesses of a few monolayers or more at temperatures of $\approx 260 \mathrm{~K}$ (Bartels-Rausch et al., 2012b). Because the surface disorder is not a true liquid and has distinctly different structural properties from a liquid (Bartels-Rausch et al., 2012b), we refer to snow with a pronounced surface disorder as dry snow.

The surface disorder triggers two key questions that are a topic of on-going controversy in atmospheric and cryospheric science (Knight, 1996b; Baker and Dash, 1996; Knight, 1996a; Bartels-Rausch et al., 2012b; Domine et al., 2013). Does the surface disorder change the interaction with trace gases compared to a more rigid surface at colder temperatures? And, does it interact with trace gases in a similar way to how liquid water would? In their pioneering work, McNeill et al. $(2006,2007)$ addressed the first question and concluded that surface disorder on ice changes the uptake of trace gases, i.e. $\mathrm{HCl}$, drastically: instead of a short-term and limited uptake as typically observed for surface adsorption of trace gases to ice, a long-lasting uptake regime was observed on ice samples that showed a pronounced surface disorder. These results imply that uptake in the presence of surface 
disorder is based on fundamentally different processes compared to adsorption to solid surfaces and thus calls for a specific parameterization.

The first aim of this study was thus to determine the extent to which sorption processes impact the diffusion of volatile organics through a dry snowpack. By comparing observed diffusivities to simulations based on the air-liquid partitioning coefficients and on the air-solid partitioning, the focus is placed on the question concerning which of the two parameterizations is superior to describe the interaction of trace gases with snow. A previously developed experimental setup that allows the diffusion of trace gases into artificial snow samples to be quantified was used (Pinzer and Schneebeli, 2009; Pinzer et al., 2010). A key feature is that the structure of the snow is analysed in detail using X-ray-computed tomography (Kerbrat et al., 2008).

\subsection{Surface interaction and grain boundaries}

Grain boundaries are defined as contact area between individual ice grains. Diffusion along grain boundaries is naturally faster than diffusion through ice crystals (Thibert and Domine, 1997; Huthwelker et al., 2006). In addition, diffusion into the volume that they enclose might possibly be another explanation for the observed long-lasting uptake of trace gases to ice and snow (Huthwelker et al., 2006; Kerbrat et al., 2010; Bartels-Rausch et al., 2012b). Indeed, Kerbrat et al. (2010) observed a significant diffusive bulk uptake of HONO into polycrystalline ice that increased the overall uptake of HONO to snow at temperatures $\geq 240 \mathrm{~K}$. In contrast, in experiments with snow samples that tended to be composed of single crystal snow grains and thus have a low grain boundary density, no bulk uptake was detected (Pinzer et al., 2010). The authors argued that the difference in the grain boundary content might explain the different long-term fate of HONO for the two samples, but conclusive results could not be drawn as a detailed analysis of the grain boundaries was lacking. Additional uncertainty comes from the use of two different experimental techniques, a snow diffusion experiment, as used in this study, and a packed bed flow tube study for the polycrystalline snow.

In this light, a second aim of this study was to explore whether or not the effective diffusivity of a trace gas is reduced in samples that have an artificially high amount of grain boundaries, but otherwise similar geometric properties. To do this, we took advantage of recent, in-detail characterizations of grain boundaries in snow samples (Riche et al., 2012a,b).

\subsection{Affinity of trace gases to snow}

In this study, acetone and methanol were chosen to investigate the diffusivity in snow and the impact of grain boundaries. First, both are of environmental significance, because volatile organics are an important source of atmospheric $\mathrm{HO}_{\mathrm{x}}$

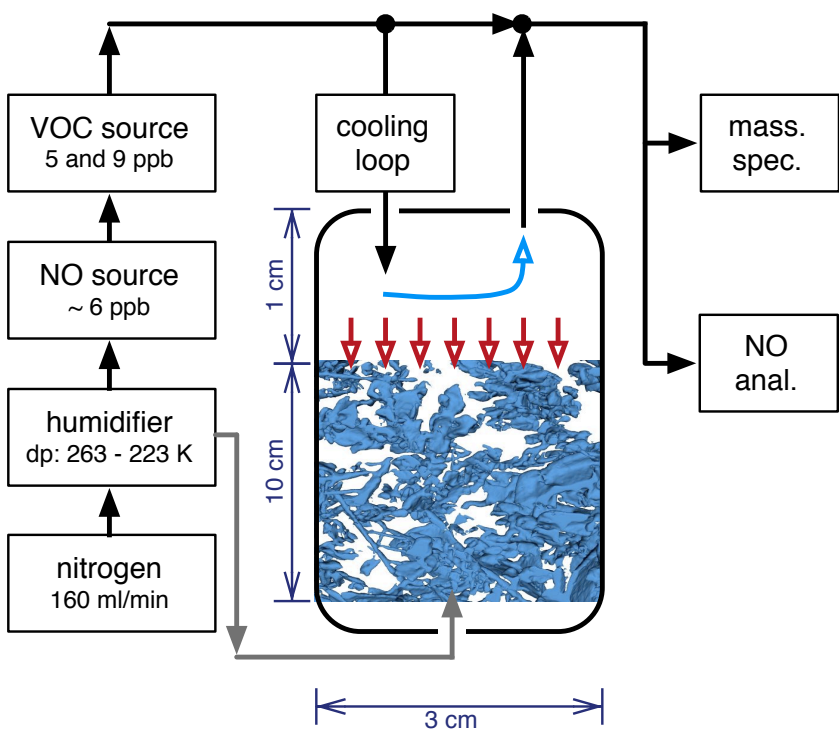

Fig. 1. Illustrative scheme of the experimental set-up showing the snow diffusion chamber. A $\mathrm{N}_{2}$ flow containing traces of acetone, methanol, and NO is passed over a snow sample (blue arrow). The trace gases diffuse into the porous snow sample from the headspace (red arrows). Before the experiments the sample can be purged to remove volatile impurities (grey arrow). Dew point is denoted as dp, filled circles represent three-way valves, and NO is added to confirm correct preparation of the snow samples (see text for details).

radicals. Second, the surface adsorption has been studied for both compounds in great detail in laboratory experiments and molecular dynamics simulations (Picaud and Hoang, 2000; Marinelli and Allouche, 2001; Hudson et al., 2002; Winkler et al., 2002; Domine and Rey-Hannot, 2002; Guimbaud et al., 2003; Bartels-Rausch et al., 2004; Collignon and Picaud, 2004; Peybernès et al., 2004; Bartels-Rausch et al., 2005; Jedlovszky et al., 2006; Behr et al., 2006; Abbatt et al., 2008; Hantal et al., 2008; Hammer et al., 2009; Starr et al., 2011). These studies give a sound basis for investigating the role of surface adsorption on diffusive transport in snow. Third, molecular dynamics studies show that methanol is preferentially incorporated into the upper ice surface region at temperatures of $250 \mathrm{~K}$, while at lower temperatures it exclusively stays on the surface (Collignon and Picaud, 2004). Molecular dynamic simulations at such high temperatures have not been performed to study the acetone adsorption. Intuitively, one would expect that the larger acetone is less well taken up into the ice compared to the smaller methanol. Taken together, these results indicate that methanol uptake might be more affected by bulk uptake than that of acetone. In this study, both trace gases were dosed simultaneously to the same snow sample to directly compare how the long-term interaction with ice impacts diffusion. 


\section{Experimental method}

The experimental set-up has been adapted from Pinzer et al. (2010) and is illustrated in Fig. 1. Central to the experimental procedure is that trace gases are passed over a snow sample and their slow diffusive loss into the porous snow is monitored using a chemical ionization mass spectrometer.

\subsection{Sample preparation and characterization}

Two types of artificial snow were used in this work: one type, which we refer to as snow-maker snow, was prepared by exposing thin nylon wires to water vapour in a cold room at $248 \mathrm{~K}$ (Löwe et al., 2011). Sublimation of de-mineralized water kept at $303 \mathrm{~K}$ produced the required water fluxes. Its production thus mimics how snowflakes nucleate in the atmosphere. The produced snow was stored for 6 weeks at $268 \mathrm{~K}$. The accelerated sintering and isothermal metamorphism during this storage resulted in small rounded grains. For the other snow type, hereafter shock-frozen snow, small ice spheres were rapidly frozen by spraying ultra pure water (MilliQ quality, $0.05 \mu \mathrm{S}$ ) into liquid nitrogen. The samples were annealed at least for 10 days at $243 \mathrm{~K}$, during which time their appearance changed form milky-white to shinyclear. Samples were prepared from either snow type by sieving the snow to a fraction of 500-600 $\mu \mathrm{m}$ in diameter, filling it into the sample holder - referred to as the snow diffusion chamber (Sect. 2.2) - and purging it over night with a stream of nitrogen in order to minimize contamination with volatile organics. This handling was done in a freezer at $243 \mathrm{~K}$, and the purge gas was humidified to the vapour pressure over the snowpack sample. Prior to use, the purge gas was disconnected and the gas inlet on the snow diffusion chamber was sealed.

The porosity and surface area of the snow in the snow diffusion chamber were extracted by image processing from $\mathrm{X}$ ray-computed micro-tomography reconstructions derived on a Scanco $\mu$ CT 80 (Kerbrat et al., 2008; Pinzer and Schneebeli, 2009; Riche et al., 2012a,b). For this, the sample was sieved to a fraction of 500 to $600 \mu \mathrm{m}$ in diameter, stored in a closed glass vessel for 1 day, and filled into a cylindrical tomography sample holder $(0.4 \times 8 \mathrm{~cm})$ to create the porous snow sample. Before the X-ray computed micro-tomography, the snow-maker samples were stored at $243 \mathrm{~K}$ for 1 week, the shock-frozen samples at $254 \mathrm{~K}$ for 3 weeks. The tortuosity was calculated based on this microstructure by a finite element simulation of the temperature field in porous snow samples, as described by Kaempfer et al. (2005). The grain boundaries of the shock-frozen samples were analysed using a stereological method (Riche et al., 2012b). For these measurements the structure of the porous snow samples was fixed with diethyl phthalate. This fixation is necessary to cut thin sections of 1 to $2 \mathrm{~cm}^{2}$ and $150 \mu \mathrm{m}$ thickness of the porous snow samples. The slicing and analysis of the thin sections' grain boundary content under the polarization microscope boundary content was done in a cold room at $253 \mathrm{~K}$.

When dosing trace gases to ice, it is important to consider the phase diagram to ensure that work is done within the ice stability regime. Unfortunately, the water-methanol, water-acetone, and the water-acetone-methanol phase diagrams are not known. Nevertheless, melting of the ice samples at $263 \mathrm{~K}$ can be excluded, because the melting point depressions of either organics are too low (Flick, 1998). At colder temperatures, we have direct spectroscopic evidence from previous work that ice is the stable phase upon adsorption of acetone at temperatures of $218 \mathrm{~K}$ (Starr et al., 2011).

\subsection{Experimental set-up}

Acetone and methanol concentrations of $1 \times 10^{11}$ molecules $\mathrm{cm}^{-3}$ and $2 \times 10^{11}$ molecules $\mathrm{cm}^{-3}$, respectively, were simultaneously dosed to the headspace of the snow diffusion chamber by passing a carrier gas $\left(\mathrm{N}_{2}\right.$, Carbagas, $\left.99.999 \%\right)$ over permeation tubes (VICI dynamical) inside a permeation oven (VICI dynacalibrator). Prior to picking up the organic trace gases, the carrier gas was humidified by passing it over an ice surface so that the dew point of water in the gas flow matched the temperature of the snow sample. Flows of the carrier gas were controlled by mass flow controllers (Brooks 5850) or flow regulators (Voegtlin red-y) with an accuracy of $1 \%$ or better. Before entering the snow diffusion chamber, the gas flow was cooled to the temperature of the snow sample. Additionally, traces of NO were dosed to the carrier gas along with acetone and methanol. NO does not interact with the ice surfaces and its diffusion behaviour has been well characterized (Pinzer et al., 2010). Its loss from the carrier gas and the time profiles of recovery were carefully examined to identify and discard experiments where systematic errors, such as small leaks in the sample holder, or cracks in the snowpack sample, occurred.

Methanol and acetone were detected using a chemical ionization mass spectrometer, as previously described (BartelsRausch et al., 2005; Ulrich et al., 2012). Water clusters from a Po-210 source or from a corona discharge served as ionization reagents at $20 \mathrm{mbar}$ pressure. Methanol and acetone were detected as their positively charged water clusters. The NO concentration profile was recorded simultaneously to the mass spectrometry data by means of a chemiluminescence analyser (eco physics).

The central part of the experiment was the snow diffusion chamber: a gas-tight, cylindrical sample holder that is made entirely of polytetrafluoroethylene (PTFE) teflon and consists of two parts. The upper part serves as empty headspace with the gas dosing and exit. It has a volume of $20 \mathrm{ml}$, and the carrier gas passes through it at atmospheric pressure with a flow rate of $160 \mathrm{ml} \mathrm{min}^{-1}$ (given at standard temperature and pressure). Below that, the porous snow sample fills a total volume of $96 \mathrm{ml}$. This $\approx 10 \mathrm{~cm}$-deep porous snow sample 
has contact to the gas in the headspace with an area of this interface of $\approx 10 \mathrm{~cm}^{2}$. The entire snow diffusion chamber rests inside a temperature-regulated thermo-jacket. Neither methanol nor acetone showed any retention in the empty sample holder down to $223 \mathrm{~K}$.

\subsection{Diffusion profiles}

The loss of either trace gas from the carrier gas and the time profile of recovery were the main observables of this study. To derive these recovery profiles, the signal intensity in the absence of methanol and acetone was recorded for $15 \mathrm{~min}$ (background), followed by the intensity in the presence of both organics and with the sample holder and headspace bypassed for $30 \mathrm{~min}$ (full intensity); then the flow was passed via the sample holder for $60 \mathrm{~min}$, followed by measurements of the full intensity and of the background. Any drifts in the background or in the full intensity signal were corrected by fitting the respective traces. The data shown in this work are averages of 2-3 individual experimental runs.

\subsection{Simulation}

To derive the diffusive loss of volatile organics from the headspace into the snowpack sample, a numerical simulation was used. For non-interacting species, the term $1 /\left(1+r_{\mathrm{sp}} \times\right.$ $K_{i} \times S S A$ ) in Eq. (1) is negligible, and Pinzer et al. (2010) have developed an analytic solution to the one-dimensional diffusion problem into a finite volume (Fick's second law):

$$
\frac{\partial c}{\partial t}=D_{\mathrm{eff}} \frac{\partial^{2} c}{\partial x}
$$

where $c$ is the concentration of trace gas in the interstitial air of the porous snow sample. The analytic solution was successfully used to describe the loss of $\mathrm{NO}$ and $\mathrm{NO}_{2}$ from the headspace into the porous snow sample (Pinzer et al., 2010). However, it is only applicable if the flux into the snow is small, because a constant gas-phase concentration at the snow-air interface at $\mathrm{c}(\mathrm{x}=0)$ was employed as the boundary condition.

For the general case of strong uptake to the ice, the gasphase concentration in the headspace drops rapidly when the carrier gas is first routed through the snow diffusion chamber. This is due to fast adsorption to the top surface of the porous snow sample; eventually the gas-phase concentration in the headspace relaxes back to equilibrium. Thus, the approximation of a constant boundary condition cannot be applied. Instead, we treat the full flux balance in the headspace numerically. The flux balance is given by

$c_{0} \times F=c_{\text {out }} \times F+j_{\text {diff }} \times A$.

Here, $c_{0}$ is the concentration of trace gas entering the headspace with the carrier gas, $c_{\text {out }}$ is the concentration of trace gas in the carrier gas at the exit of the headspace, $F$ is the gas flow through the headspace, $A$ is the cross-section area of the snow cylinder, and $j_{\text {diff }}$ is the diffusion flux into the porous sample. We assume ideal mixing in the headspace volume, so that the concentration right above the snow equals $c_{\text {out }}$. This assumption seems well justified, because the total flux of trace gases from the headspace to the snow sample rarely exceeds $20 \%$. With the diffusion flux through a porous medium as given in Eq. (2) (Schwarzenbach et al., 2003), Eq. (3) can be rearranged to yield the boundary condition at the snow-air interface:

$c_{0} \times F=c(x=0) \times F-A \times \phi \times D_{\text {air }} \frac{\partial^{2} c(x=0)}{\partial^{2} x}$.

Calculations and analysis were done with MATLAB.

\section{Results}

\subsection{Diffusion profiles}

We first studied the diffusive transport of the volatile organics acetone and methanol through a snow-maker snow sample, the freezing process of which mimics nucleation of ice crystals in the atmosphere. Figure 2 shows the primary observable of these experiments, the mean experimentally observed recovery profiles. The observed profiles of individual experimental runs at each temperature were almost identical: the standard deviations of the three individually measured recoveries at $10 \mathrm{~min}, 30 \mathrm{~min}$, and $60 \mathrm{~min}$ were around $10 \%$ or better. The reproducibility of the experiments at $243 \mathrm{~K}$ was, at $\approx 1 \%$, significantly better and the scatter in the profiles much less pronounced, because different ionization conditions in the mass spectrometer were used that improved the signal-to-noise ratio.

The first observation is that the gas-phase concentrations in the headspace recover quickly, indicating that the overall losses from the overlaying gas phase by gas-phase diffusion into the porous snowpack are small, and have a pronounced temperature dependence. At $263 \mathrm{~K}$ the observed profiles show, within the reproducibility of $10 \%$, an immediate recovery to the initial gas-phase concentration of acetone and methanol and thus resemble the profiles of NO (Pinzer et al., 2010), a trace gas that does not interact with the ice surface at those temperatures (Bartels-Rausch et al., 2002). Similar fast recoveries have been observed at $253 \mathrm{~K}$ (data not shown). This indicates that under these warm conditions, diffusion through the dry snowpack is fast for both volatile organics. Given the small air volume of $55 \mathrm{~cm}^{3}$ in the porous snow sample, the concentration gradient is eliminated rapidly and diffusion from the carrier gas stops.

The effective diffusive loss into the snowpack is significantly enhanced at cold temperatures for both acetone and methanol, and at the lowest temperature studied $(223 \mathrm{~K})$ neither volatile organic fully recovers during the course of this experiment. The observed slower diffusive transport is driven by air-ice interactions of either trace gas. First, recovery profiles of non-interacting trace gases, such as NO, do not show 

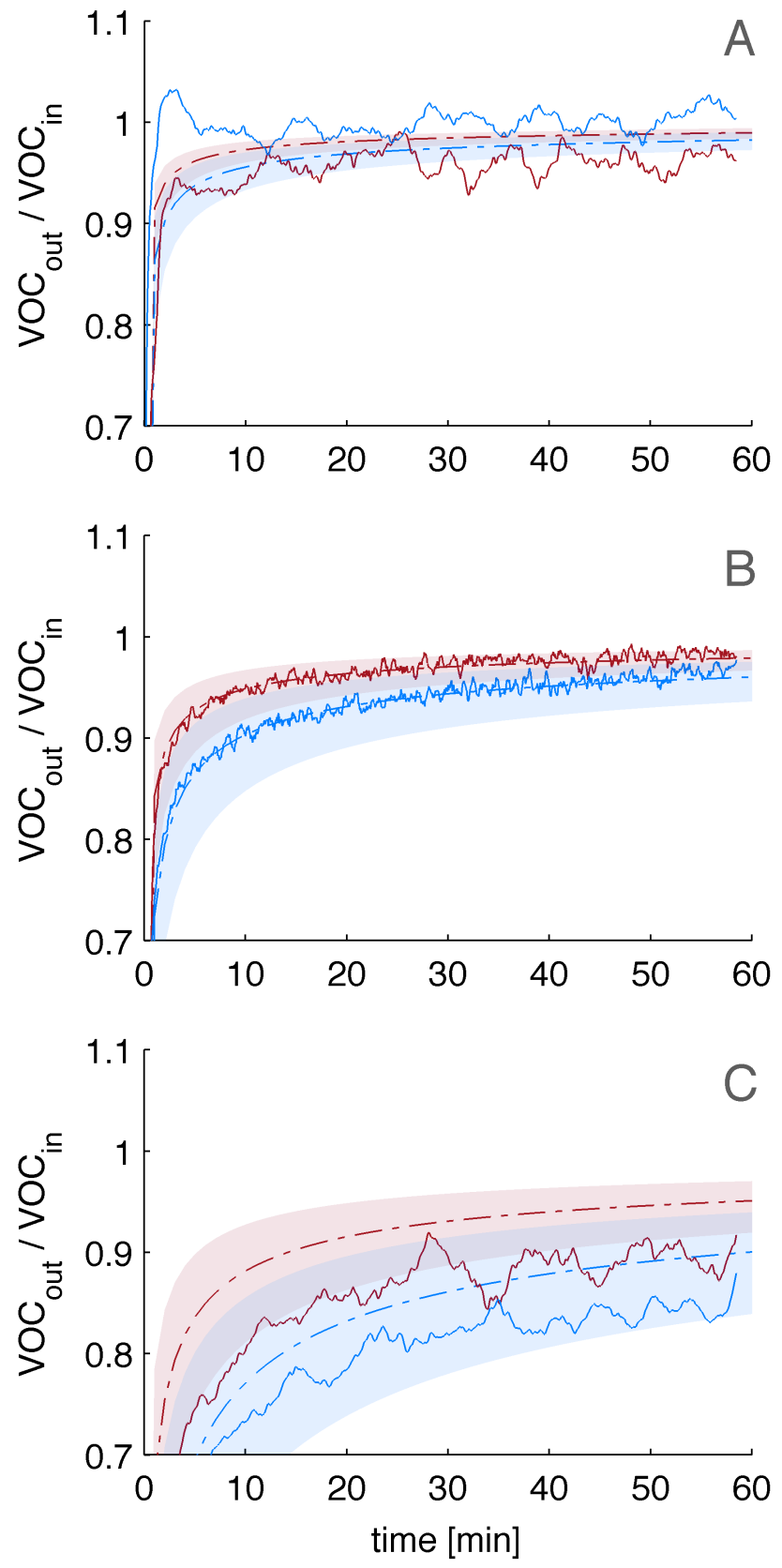

Fig. 2. Mean experimental recovery profiles (solid lines) of methanol (blue) and acetone (red) at different temperatures ((A) $263 \mathrm{~K}(n=3)$, (B) $243 \mathrm{~K}(n=2)$, (C) $223 \mathrm{~K}(n=3))$ in packed snow-maker snow. Also shown are results from numerical simulations of the recovery (dashed line) with uncertainties (shaded area), where the air-ice partitioning (Langmuir coefficient) was used to parameterize the effective diffusivity.

such a strong temperature dependence (Pinzer et al., 2010). Second, methanol recovers slower than acetone, which is consistent with its stronger interaction with ice (Crowley et al., 2010).

\subsection{Simulation - Langmuir vs. Henry}

To extract more quantitative data from the experiments, the observed recovery profiles were compared to simulations based on the snow sample's porosity and tortuosity, as well as on the specific interactions of methanol and acetone with ice as given in Eq. (1). Table 1 lists calculated values of the effective diffusivity for acetone and methanol through the porous snow samples at $243 \mathrm{~K}$. In this particular sample, the effective diffusivity is slower than the diffusivity in air by a factor of 50 or more. For this calculation, and the simulations shown in Fig. 2, the gas-phase diffusion constants were taken from Winkelmann (2007a,b), and extrapolated to the temperature of the experiment, based on the reported temperature dependence of methanol gas-phase diffusion (Winkelmann, 2007a): $K_{\text {LinC }}$ and their temperature dependence were taken from Crowley et al. (2010); $r_{\mathrm{sp}}$ was calculated based on the porosity and the snow density as measured in this study and given in Table 1. Also shown is the uncertainty in the simulation results (Fig. 2 and Table 1). The uncertainty was assessed by repeating the calculations, taking the published error range of $K_{\text {LinC }}$ (Crowley et al., 2010) as input and changing the other input parameters by $10 \%$ each.

The results show that acetone recoveries are very well captured and follow the simulations closely (Fig. 2). One exception is data at $223 \mathrm{~K}$, where the mean of the experimental runs lies on the lower edge of the simulation. Given the uncertainties of the experimental results and in the simulation, the agreement is good. Methanol shows a very good agreement except at $263 \mathrm{~K}$, where the observed recovery is faster than the simulation and also compared to the recovery of NO. This is presumably an artefact by the ionization schemes in the mass spectrometer. Release of methanol from potentially contaminated samples was excluded as a reason for these high recoveries. Given that the diffusivity of methanol is not influenced by surface interactions, any temperature-induced change to the ice surface structure can also not explain a faster recovery than predicted based on solid ice-air partitioning.

Two conclusions can be drawn. First, surface interactions have a strong impact on diffusive transport through the open pore space of dry snow and dominate the diffusivity at temperatures where adsorption equilibrium predicts a significant surface concentration. Second, the Langmuir coefficient, used to parameterize the reversible surface adsorption of trace gases to ice, describes the interaction of trace gases with the ice surface during diffusion well.

We also simulated the diffusive loss into the dry snowpack based on the reversible uptake to a liquid layer covering the surface of the individual ice spheres, using the air-water partitioning coefficients based on Henry's law extrapolated to the temperature of the experiment. The results of these simulations are compared to the observed recovery profiles in Fig. 3. Such an approach is often used in current snow chemistry models to parameterize air-snow exchanges with dry 
Table 1. Calculated effective diffusion constant ( $\left.D_{\text {eff }}\right)$ of methanol and acetone for snow-maker snow at $243 \mathrm{~K}$. Calculation were done based on Eq. (1) with the solid ice/air ratio $\left(r_{\mathrm{sp}}\right)$, the gas-phase diffusion constant $\left(D_{\text {air }}\right)$ and the Langmuir partitioning coefficient $\left(K_{\mathrm{LinC}}\right)$ as input.

\begin{tabular}{lcc}
\hline & Methanol & Acetone \\
\hline $\begin{array}{l}D_{\mathrm{eff}} \\
{\left[\mathrm{cm}^{2} \mathrm{~s}^{-1}\right]}\end{array}$ & $\begin{array}{c}8 \times 10^{-4} \\
(+53 \%-109 \%)\end{array}$ & $\begin{array}{c}1 \times 10^{-3} \\
(+51 \%-104 \%)\end{array}$ \\
\hline$r_{\mathrm{sp}}$ & 225 & 225 \\
{$\left[\mathrm{~kg} \mathrm{~m}^{-3}\right]$} & $\pm 10 \%$ & $\pm 10 \%$ \\
\hline$K_{\mathrm{LinC}}$ & $7 \times 10^{-1}$ & $3 \times 10^{-1}$ \\
{$[\mathrm{~cm}]$} & $(+159 \%-63 \%)$ & $(+159 \%-63 \%)$ \\
\hline$D_{\mathrm{air}}$ & $7 \times 10^{-2}$ & $5 \times 10^{-2}$ \\
{$\left[\mathrm{~cm}^{2} \mathrm{~s}^{-1}\right]$} & $\pm 10 \%$ & $\pm 10 \%$ \\
\hline
\end{tabular}

snow (Thomas et al., 2011; Bartels-Rausch et al., 2012b). As shown in Fig. 3, the air-liquid partitioning is not suited to describe the observed recovery profiles at temperatures at and below $243 \mathrm{~K}$. For these simulations, the distribution of the volatile organics between ice and air was parameterized as uptake into a 1-30 nm-thick liquid covering the total specific surface area of the snow sample. Henry's law coefficients were taken from Snider and Dawson (1985) and extrapolated to the temperatures of the snow sample. The calculations reveal that at $263 \mathrm{~K}$ the results are invariant to the simulations based on the air-ice partitioning coefficient, as both results show a negligible influence of partitioning to the snow surface on the diffusive transport (Fig. 2 and 3). At colder temperatures the simulations based on Henry's law coefficients predict faster recoveries than observed for acetone, and even more so for methanol (Fig. 3). At $223 \mathrm{~K}$ Henry's law coefficients still predict a negligible influence of partitioning to the snow surface for the diffusion of both methanol and acetone.

From this we conclude that the surface interaction with dry snow during the diffusive process can be better described as air-solid partitioning at temperatures up to $263 \mathrm{~K}$. This conclusion is in-line with a number of earlier measurements that determined the reversible adsorption of volatile trace gases to ice and showed that the interaction of trace gases with ice is generally well described by an air-solid partitioning constant at temperature up to $\approx 240 \mathrm{~K}$ and for some species, such as HONO, even up to $260 \mathrm{~K}$ (Crowley et al., 2010). Describing interactions with ice surfaces based on properties of liquid water is a very controversial topic of debate (Bartels-Rausch et al., 2012b). Our results show that parameterizing the ice surface with properties of a super-cooled solution is indeed an over-simplification. For dissolution into the disordered interface at the ice surface to be an important factor, the volume of this interface needs to be large enough to accommodate significant amounts of solutes, and the solvation mechanism needs to be similar to that of liquid water. Current in-
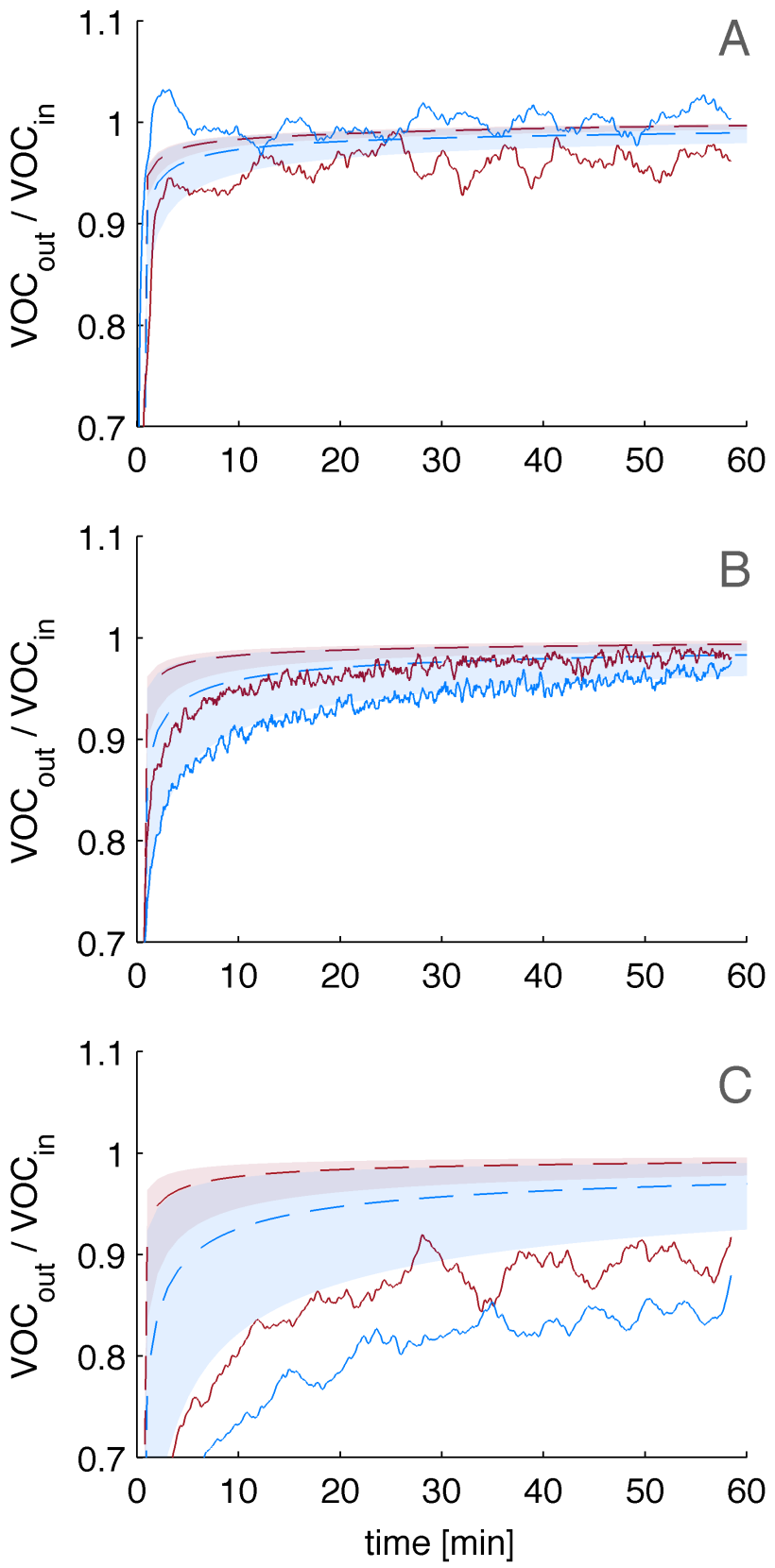

Fig. 3. Experimental recovery profiles (solid lines) of methanol (blue) and acetone (red) at different temperatures ((A) $263 \mathrm{~K}$, (B) $243 \mathrm{~K}$, (C) $223 \mathrm{~K}$ ) in snow-maker snow. Also shown are results from numerical simulations of the recovery (dashed line) with uncertainties (shaded area), where the air-water partitioning (Henry's law coefficient) was used to parameterize the effective diffusivity.

vestigations of the thickness of this disordered interface give no conclusive picture, but most agree that it is a few tens of $\mathrm{nm}$ at most at temperatures below $263 \mathrm{~K}$ (Bartels-Rausch et al., 2012b). It has been argued that strong acids enhance the thickness of the disordered interface significantly and that 
this might provide a feedback that enhances the uptake (McNeill et al., 2006, 2007). Similar processes might also operate during the adsorption of volatile organics. However, recent direct surface-sensitive observations of the structure of water molecules upon adsorption of volatile organics, such as acetone and acetic acid, have clearly shown that at temperatures of $243 \mathrm{~K}$ the thickness of the disordered interface is not significantly increased, as those measurements give no indication that the thickness is larger than a few $\mathrm{nm}$ upon adsorption of these organic traces (Starr et al., 2011; Krepelova et al., 2013). These surface-sensitive studies further clearly show that the adsorbed volatile organics remain on the surface of the ice and do not enter deep into the crystal structure. Based on depth profiles of carbon (from acetic acid) in the ice surface, Krepelova et al. (2013) showed that acetic acid does not reach depths deeper than $2 \mathrm{~nm}$ and concluded that reversible surface adsorption describes this situation well. In conclusion, this study gives clear evidence that, at temperatures where the surface disorder is thin, air-liquid partitioning does not adequately describe the interaction with the ice surface. That the interaction of many volatile organics with ice is a purely surface process is supported by surfacesensitive spectroscopy that gives no indication for dissolution of acetic acid in the ice. An exception for this adsorptiondominated interaction is formaldehyde. Barret et al. (2011b) have shown that this small organic trace gas forms solid solutions with ice and that this solution equilibrium with the ice crystal can explain observed formaldehyde exchanges between the air and the surface snow in the Arctic (Barret et al., 2011a).

At temperatures approaching the melting point, but low enough to prevent (partial) melting, the surface interaction of these volatile organics is too small to significantly impact the diffusion in dry snow, and this is reflected by both parameterizations.

\subsection{Impact of grain boundaries}

To study the effect of grain boundaries on the diffusion of trace gases through porous snow, experiments were performed with a second type of snow sample with a very high grain boundary content. Figure 5 shows the morphology of the shock-frozen snow as viewed under a polarization microscope. The contact area between individual ice spheres per volume of the snow sample, hereafter specific grain boundary area, adds $2 \mathrm{~mm}^{2} \mathrm{~mm}^{-3}$ (Riche et al., 2012a). Additionally, about $60-70 \%$ of those spheres consist of several smaller ice crystals, so the total specific grain boundary area equals $10 \mathrm{~mm}^{2} \mathrm{~mm}^{-3}$ (Riche et al., 2012a). In contrast, natural snow freezes by condensation of vapour in the gas phase, and individual snow spheres are always single crystals (Riche et al., 2012b). The snow-maker snow used in this study was not analysed for its grain boundary content, but we argue that it is also composed of single crystals and that the total grain boundary area is only given by the contact area between in-
Table 2. Properties of the different types of snow samples as determined by stereology (grain boundary area) and by X-ray-computed micro-tomography. SSA is the specific surface area and GBA the total grain boundary area

\begin{tabular}{llcc}
\hline & & Shock-frozen & Snow-maker \\
\hline Porosity & {$[-]$} & 0.42 & 0.57 \\
Density & {$\left[\mathrm{kg} \mathrm{m}^{-3}\right]$} & 531 & 393 \\
SSA & {$\left[\mathrm{cm}^{2} \mathrm{~g}^{-1}\right]$} & 116 & 211 \\
Tortuosity & {$[-]$} & 1.54 & 1.48 \\
GBA & {$\left[\mathrm{mm}^{2} \mathrm{~mm}^{-3}\right]$} & 10 & 2 \\
\hline
\end{tabular}

dividual ice grains. Based on the measured contact area of ice spheres in the shock-frozen snow and accounting for the lower density of snow-maker snow (Table 2), one can estimate a total specific grain boundary area of $1.5 \mathrm{~mm}^{2} \mathrm{~mm}^{-3}$. Using this estimate, the specific grain boundary area in the two snow samples differs by a factor of 7 .

The impact of this large difference in grain boundary content on the diffusion of methanol and acetone through dry snow is shown in Fig. 4. Here, the experimental recovery profiles are plotted as a ratio of snow-maker to shock-frozen snow, for three temperatures. Figure 4 clearly shows that a larger grain boundary content does not enhance the interaction of methanol and acetone with the ice phase during diffusion through porous snow. The recovery profiles over packed shock-frozen polycrystalline ice spheres agree within $10 \%$ to the recovery profiles over snow-maker snow. That is, the plotted ratio in Fig. 4 lies within the $90-110 \%$ interval. A better agreement of the observed profiles was not expected, as the samples differed slightly in surface area and microstructure (Table 2). This negligible impact of grain boundaries in dry snow holds for temperatures spanning 263 to $223 \mathrm{~K}$. In principle, grain boundaries have the potential to impact the uptake of trace gases in two ways. First, the microscopic surface structure differs at grain boundaries from the free surface, and this may directly impact the adsorption equilibrium, e.g. by providing sites of energetically preferred adsorption (Donaldson et al., 2012). For example, McNeill et al. (2007) have observed two different adsorption modes for ice samples with varying grain size and have suggested that a particular reversible adsorption mode takes place at grain boundaries. Second, grain boundaries may also provide a channel through which adsorbates can diffuse rapidly away from the surface (Thibert and Domine, 1997) and which may serve as long-term reservoirs for adsorbates (Huthwelker et al., 2006).

Our results show that for acetone the number of grain boundaries in the sample affects neither the short-term nor the long-lasting uptake. This finding is in agreement with results from earlier experiments of our group, where the adsorption of acetone to single-crystalline ice and 

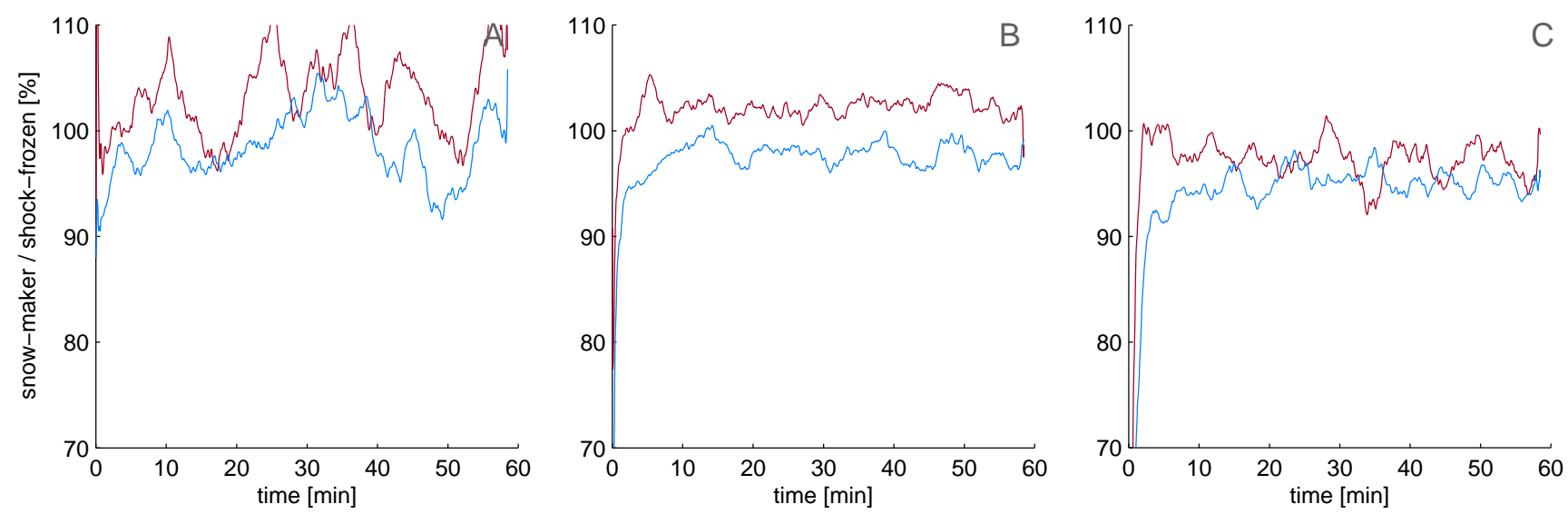

Fig. 4. Comparison of diffusivities in polycrystalline and single-crystalline samples. Shown is the ratio of the observed recovery profiles of methanol (blue) and acetone (red) at different temperatures ((A) $263 \mathrm{~K}$, (B) $243 \mathrm{~K}$, (C) $223 \mathrm{~K}$ ) for a single-crystalline and polycrystalline sample.

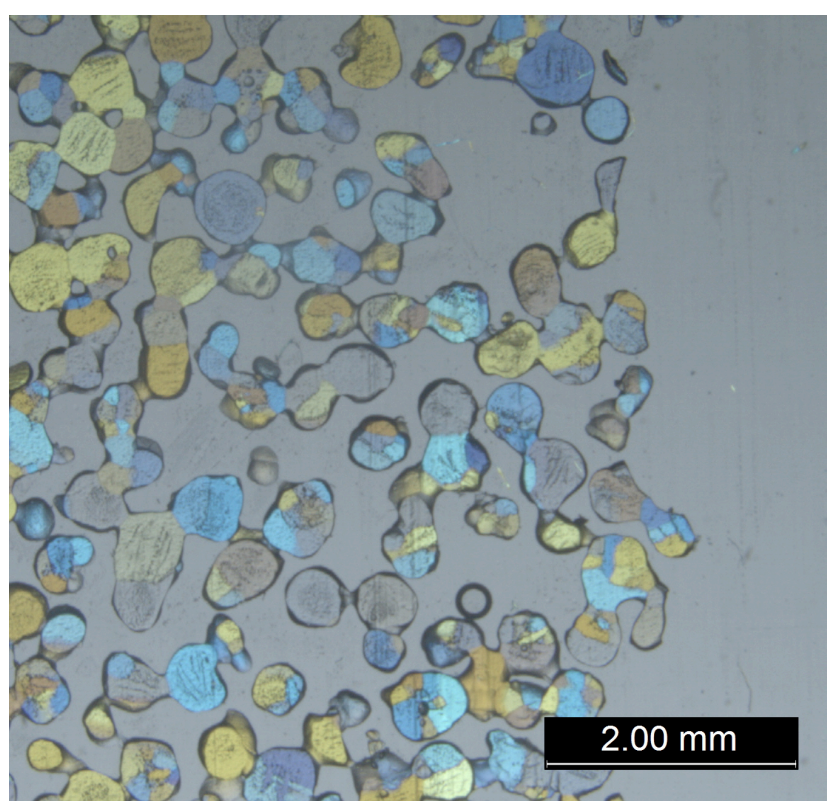

Fig. 5. Thin slice of a polycrystalline ice sample as seen under a polarization microscope. Coloured areas visualize individual ice crystals. The slice also shows the porosity of the snow sample.

polycrystalline ice was investigated in a packed bed flow tube (Bartels-Rausch et al., 2005). This study verifies this conclusion and expands it to warmer temperatures and longer timescales, where diffusive processes become increasingly dominating (Kerbrat et al., 2010), and does so using a wellcharacterized snow sample. The earlier experiments were done in the temperature range of 198 to $223 \mathrm{~K}$, and lasted approximately 20 minutes. Further support for the irrelevance of grain boundaries for short-term adsorption comes from molecular dynamics calculations that have shown that interaction of acetone with the neat ice surface is energetically more favourable than the interaction with ice at grain boundaries (Hammer et al., 2009).

The interaction of methanol with different types of ice has not been investigated before. Results from a molecular dynamics study indicate that methanol adsorbs to ice by forming hydrogen bonds at the surface at $210 \mathrm{~K}$ and by dissolving into the upper water molecule layers of the ice crystal at $250 \mathrm{~K}$. Given that a dissolved molecule may diffuse more easily into grain boundaries, one would have expected different recovery profiles of methanol on the two types of snow in our experiments. However, the results presented here show that, even for this highly soluble molecule with its rather small size, surface adsorption dominates its interaction with polycrystalline ice on timescales of one hour.

In conclusion, solid-phase diffusion into grain boundaries does not impact the gas-phase transport of acetone and methanol, and probably other volatile organics, through a porous snow on timescales relevant for diffusive transport. This conclusion might not hold for those species that easily diffuse into the ice lattice and form solid solutions there. For those species, for example formaldehyde, air-snow exchanges can be dominated by diffusion and uptake into the bulk ice (Barret et al., 2011a,b). It would be interesting to study whether these molecules with their high affinity for solid-state diffusion dominate the interaction with snow on timescales relevant for diffusive transport. 


\section{Conclusions}

In this study the diffusive transport of methanol and acetone into porous snow was investigated by monitoring the concentration of the two gases in the air above a dry snow sample.

- At temperatures above $243 \mathrm{~K}$ diffusion of methanol and acetone into porous snow is fast and identical to that of NO, a gas that does not interact with ice surfaces. At lower temperatures ( $243 \mathrm{~K}$ and $223 \mathrm{~K}$ ) diffusion of both organics is significantly slowed with methanol diffusing slower than acetone. This trend reflects the tendency to adsorb to ice surfaces.

- The effective diffusivities of both gases, as well as their temperature dependence, can be well described by taking into account the snow geometric properties and surface interactions. Results from our numerical simulations show that surface interactions can dominate diffusivity at low temperatures, and that the air-solid partitioning coefficient describes the reversible interaction with trace gases well.

- By comparing the diffusion profiles of acetone and methanol through porous snow samples which differed in their total grain boundary content, we found that grain boundaries neither enhance surface adsorption nor impede diffusion through the open pore space of snow on the timescale of $1 \mathrm{~h}$.

\section{Atmospheric implication}

This study shows that the diffusion of acetone and methanol through surface snow under most temperatures typical for the Arctic and the non-polar cryosphere is fast. As a consequence, the release of acetone and methanol from the snowpack to the overlaying air is rapid, ensuring an almost instant exchange with the air masses, where acetone and methanol are important source of radicals (Heard et al., 2006). Further, the fast diffusion limits their residence time in the snowpack and thus the probability for chemistry there. Only under very cold conditions that may prevail in Antarctica or rarely in the Arctic will surface adsorption significantly slow the diffusive transport through snow.

More importantly, this study verifies the use of Eq. (1) to predict the diffusivity of these atmospheric trace gases through a snowpack and shows that surface adsorption is a key factor controlling this transport. Knowing the snowpack geometric properties, gas-phase diffusion, and partitioning equilibrium is sufficient to predict the diffusivity.

The air-liquid partitioning does not adequately describe the interaction with dry snow. We propose that this might also be applied to other volatile and, more interestingly, semivolatile species, for which surface adsorption dominates the interaction with snow. It should also apply to snow and ice of different microstructures, including frozen ice clouds.
Whether the Langmuir or Henry's law coefficient is superior to parameterize the uptake of trace gases to solid ice is an open question also in research focusing on the upper troposphere (Neu and Prather, 2012). As the interaction of trace gases with wet snow differs significantly from dry snow (Clapsaddle and Lamb, 1989; Herbert et al., 2006b; BartelsRausch et al., 2012b), this finding holds as long as the snow is dry and liquid water is not present.

The (potential) flux of these organic compounds into the grain boundaries is too small to impact their diffusive transport in the gas phase, and this will likely also hold for most larger organic molecules. For other species, such as inorganic acids or formaldehyde, grain boundaries may still present a significant sink (Huthwelker et al., 2001; Kerbrat et al., 2010).

Acknowledgements. The authors thank D. J. Donaldson for continuing support and discussion. The Swiss National Science Foundation supported the research, SNF grants 200020125179 and 200021 121857. S.N. Wren thanks the Centre for Global Change Science (CGCS) at the University of Toronto for a Graduate Student Award. The editor thanks the referees for assisting in evaluating this paper.

Edited by: V. Faye McNeill

\section{References}

Abbatt, J. P. D., Bartels-Rausch, T., Ullerstam, M., and Ye, T. J.: Uptake of acetone, ethanol and benzene to snow and ice: Effects of surface area and temperature, Environ. Res. Lett., 3, 045008, doi:10.1088/1748-9326/3/4/045008, 2008.

Baker, M. and Dash, J. G.: Comment on: Surface layers on ice by CA Knight, J. Geophys. Res., 101, 12929-12936, doi:10.1029/96JD00555, 1996.

Barret, M., Domine, F., Houdier, S., Gallet, J.-C., Weibring, P., Walega, J., Fried, A., and Richter, D.: Formaldehyde in the Alaskan Arctic snowpack: Partitioning and physical processes involved in air-snow exchanges, J. Geophys. Res., 116, D00R03, doi:10.1029/2011JD016038, 2011a.

Barret, M., Houdier, S., and Domine, F.: Thermodynamics of the formaldehyde - water and formaldehyde - ice systems for atmospheric applications, J. Phys. Chem. A, 115, 307-317, doi:10.1021/jp108907u, 2011b.

Bartels-Rausch, T., Eichler, B., Zimmermann, P., Gäggeler, H. W., and Ammann, M.: The adsorption enthalpy of nitrogen oxides on crystalline ice, Atmos. Chem. Phys., 2, 235-247, doi:10.5194/acp-2-235-2002, 2002.

Bartels-Rausch, T., Guimbaud, C., Gäggeler, H. W., and Ammann, M.: The partitioning of acetone to different types of ice and snow between 198 and 223 K, Geophys. Res. Lett., 31, L16110, doi:10.1029/2004g1020070, 2004.

Bartels-Rausch, T., Huthwelker, T., Gäggeler, H. W., and Ammann, M.: Atmospheric pressure coated-wall flow-tube study of acetone adsorption on ice, J. Phys. Chem. A, 109, 4531-4539, doi:10.1021/Jp0451871, 2005. 
Bartels-Rausch, T., Bergeron, V., Cartwright, J., Escribano, R., Finney, J., Grothe, H., Gutiérrez, P., Haapala, J., Kuhs, W., Pettersson, J., Price, S., Sainz-Díaz, C., Stokes, D., Strazzulla, G., Thomson, E., Trinks, H., and Uras-Aytemiz, N.: Ice structures, patterns, and processes: A view across the icefields, Rev. Mod. Phys., 84, 885-944, doi:10.1103/RevModPhys.84.885, 2012a.

Bartels-Rausch, T., Jacobi, H. W., Kahan, T. F., Thomas, J. L., Thomson, E. S., Abbatt, J. P. D., Ammann, M., Blackford, J. R., Bluhm, H., Boxe, C. S., Domine, F., Frey, M. M., Gladich, I., Guzman, M. I., Heger, D., Huthwelker, T., Klán, P., Kuhs, W. F., Kuo, M. H., Maus, S., Moussa, S. G., McNeill, V. F., Newberg, J. T., Pettersson, J. B. C., Roeselova, M., and Sodeau, J. R.: Relationship between snow microstructure and physical and chemical processes, Atmos. Chem. Phys. Discuss., 12, 30409-30541, doi:10.5194/acpd-12-30409-2012, 2012b.

Behr, P., Terziyski, A., and Zellner, R.: Acetone adsorption on ice surfaces in the temperature range $\mathrm{T}=190-220 \mathrm{~K}$ : Evidence for aging effects due to crystallographic changes of the adsorption sites, J. Phys. Chem. A, 110, 8098-8107, doi:10.1021/jp0563742, 2006.

Choi, J., Conklin, M. H., Bales, R. C., and Sommerfeld, R. A.: Experimental investigation of $\mathrm{SO}_{2}$ uptake in snow, Atmos. Environ., 34, 793-801, doi:10.1016/S1352-2310(99)00286-1, 2000.

Chu, L., Diao, G., and Chu, L. T.: Heterogeneous interaction and reaction of HONO on ice films between 173 and $230 \mathrm{~K}$, J. Phys. Chem. A, 104, 3150-3158, doi:10.1021/jp9937151, 2000.

Clapsaddle, C. and Lamb, D.: The sorption behavior of $\mathrm{SO}_{2}$ on ice at temperatures between $30^{\circ} \mathrm{C}$ and $5^{\circ} \mathrm{C}$, Geophys. Res. Lett., 16, 1173-1176, doi:10.1029/GL016i010p01173, 1989.

Collignon, B. and Picaud, S.: Comparison between methanol and formaldehyde adsorption on ice: A molecular dynamics study, Chem. Phys. Lett., 393, 457-463, doi:10.1016/j.cplett.2004.06.085, 2004.

Crowley, J. N., Ammann, M., Cox, R. A., Hynes, R. G., Jenkin, M. E., Mellouki, A., Rossi, M. J., Troe, J., and Wallington, T. J.: Evaluated kinetic and photochemical data for atmospheric chemistry: Volume V - heterogeneous reactions on solid substrates, Atmos. Chem. Phys., 10, 9059-9223, doi:10.5194/acp-10-90592010, 2010.

Domine, F. and Rey-Hannot, L.: Adsorption isotherms of acetone on ice between 193 and 213 K, Geophys. Res. Lett., 29, 1873, doi:10.1029/2002GL015078, 2002.

Domine, F. and Shepson, P. B.: Air-snow interactions and atmospheric chemistry, Science, 297, 1506-1510, doi:10.1126/science.1074610, 2002.

Domine, F., Albert, M. R., Huthwelker, T., Jacobi, H. W., Kokhanovsky, A. A., Lehning, M., Picard, G., and Simpson, W. R.: Snow physics as relevant to snow photochemistry, Atmos. Chem. Phys., 8, 171-208, doi:10.5194/acp-8-171-2008, 2008.

Domine, F., Bock, J., Voisin, D., and Donaldson, D. J.: Can we model snow photochemistry? Problems with the current approaches, J. Phys. Chem. A, p. 130418151008006, 2013.

Donaldson, D. J., Ammann, M., Bartels-Rausch, T., and Pöschl, U.: Standard states and thermochemical kinetics in heterogeneous atmospheric chemistry, J. Phys. Chem. A, 116, 63126316, doi:10.1021/jp212015g, 2012.

Fabre, A., Barnola, J.-M., Arnaud, L., and Chappellaz, J.: Determination of gas diffusivity in polar firn: Comparison between experimental measurements and inverse modeling, Geophys. Res.
Lett., 27, 557-560, doi:10.1029/1999GL010780, 2000.

Flick, E. W.: Industrial solvents handbook (5th edition), William Andrew Publishing/Noyes, http://www.knovel.com/web/portal/ browse/display?_EXT_KNOVEL_DISPLAY_bookid=363, 1998.

Grannas, A. M., Jones, A. E., Dibb, J. E., Ammann, M., Anastasio, C., Beine, H. J., Bergin, M. H., Bottenheim, J. W., Boxe, C. S., Chen, G., Crawford, J. H., Domine, F., Frey, M. M., Guzman, M. I., Heard, D., Helmig, D., Hoffmann, M. R., Honrath, R., Huey, L. G., Hutterli, M., Jacobi, H.-W., Klan, P., Lefer, B., McConnell, J., Plane, J., Sander, R., Savarino, J., Shepson, P. B., Simpson, W., Sodeau, J. R., von Glasow, R., Weller, R., and Wolff, E. W.: An overview of snow photochemistry: Evidence, mechanisms and impacts, Atmos. Chem. Phys., 7, 4329-4373, doi:10.5194/acp-7-4329-2007, 2007.

Groffman, P. M., Driscoll, C. T., Fahey, T. J., Hardy, J. P., Fitzhugh, R. D., and Tierney, G. L.: Colder soils in a warmer world: A snow manipulation study in a northern hardwood forest ecosystem, Biogeochem., 56, 135-150, doi:10.1023/A:1013039830323, 2001.

Guimbaud, C., Bartels-Rausch, T., and Ammann, M.: An atmospheric pressure chemical ionization mass spectrometer (APCIMS) combined with a chromatographic technique to measure the adsorption enthalpy of acetone on ice, Int. J. Mass. Spectrom., 226, 279-290, doi:10.1016/S1387-3806(03)00019-8, 2003.

Hammer, S. M., Panisch, R., Kobus, M., Glinnemann, J., and Schmidt, M. U.: Simulation of absorption sites of acetone at ice: (0001) surface, bulk ice and small-angle grain boundaries, Cryst. Eng. Comm., 11, 1291-1302, doi:10.1039/b820918a, 2009.

Hantal, G., Jedlovszky, P., Hoang, P. N. M., and Picaud, S.: Investigation of the adsorption behaviour of acetone at the surface of ice. A grand canonical Monte Carlo simulation study, Phys. Chem. Chem. Phys., 10, 6369-6380, doi:10.1039/b808466a, 2008.

Heard, D. E., Read, K. A., Methven, J., Al-Haider, S., Bloss, W. J., Johnson, G. P., Pilling, M. J., Seakins, P. W., Smith, S. C., Sommariva, R., Stanton, J. C., Still, T. J., Ingham, T., Brooks, B., de Leeuw, G., Jackson, A. V., McQuaid, J. B., Morgan, R., Smith, M. H., Carpenter, L. J., Carslaw, N., Hamilton, J., Hopkins, J. R., Lee, J. D., Lewis, A. C., Purvis, R. M., Wevill, D. J., Brough, N., Green, T., Mills, G., Penkett, S. A., Plane, J. M. C., Saiz-Lopez, A., Worton, D., Monks, P. S., Fleming, Z. L., Rickard, A. R., Alfarra, M. R., Allan, J. D., Bower, K., Coe, H., Cubison, M., Flynn, M., McFiggans, G., Gallagher, M., Norton, E. G., O apos Dowd, C. D., Shillito, J., Topping, D., Vaughan, G., Williams, P., Bitter, M., Ball, S. M., Jones, R. L., Povey, I. M., O apos Doherty, S., Simmonds, P. G., Allen, A., Kinnersley, R. P., Beddows, D. C. S., Dall apos Osto, M., Harrison, R. M., Donovan, R. J., Heal, M. R., Jennings, S. G., Noone, C., and Spain, G.: The North Atlantic marine boundary layer experiment (NAMBLEX). Overview of the campaign held at Mace Head, Ireland, in summer 2002, Atmos. Chem. Phys., 6, 2241-2272, doi:10.5194/acp-6-2241-2006, 2006.

Helmig, D., Apel, E., Blake, D. R., Ganzeveld, L., Lefer, B. L., Meinardi, S., and Swanson, A. L.: Release and uptake of volatile inorganic and organic gases through the snowpack at Niwot Ridge, Colorado, Biogeochem., 95, 167-183, doi:10.1007/s10533-009-9326-8, 2009.

Herbert, B. M. J., Halsall, C. J., Jones, K. C., and Kallenborn, R.: Field investigation into the diffusion of semi-volatile or- 
ganic compounds into fresh and aged snow, Atmos. Environ., 40, 1385-1393, doi:10.1016/j.atmosenv.2005.10.055, 2006 a.

Herbert, B. M. J., Villa, S., and Halsall, C. J.: Chemical interactions with snow: Understanding the behavior and fate of semi-volatile organic compounds in snow, Ecotox. Environ. Safety, 63, 3-16, doi:10.1016/j.ecoenv.2005.05.012, 2006b.

Hudson, P. K., Zondlo, M. A., and Tolbert, M. A.: The interaction of methanol, acetone, and acetaldehyde with ice and nitric aciddoped ice: Implications for cirrus clouds, J. Phys. Chem. A, 106, 2882-2888, doi:10.1021/jp012718m, 2002.

Huthwelker, T., Lamb, D., Baker, M., Swanson, B., and Peter, T.: Uptake of $\mathrm{SO}_{2}$ by polycrystalline water ice, J. Colloid Interface Sci., 238, 147-159, doi:10.1006/jcis.2001.7507, 2001.

Huthwelker, T., Ammann, M., and Peter, T.: The uptake of acidic gases on ice, Chem. Rev., 106, 1375-1444, doi:10.1021/Cr020506v, 2006.

Jedlovszky, P., Pártay, L., Hoang, P. N. M., Picaud, S., von Hessberg, P., and Crowley, J. N.: Determination of the adsorption isotherm of methanol on the surface of ice. An experimental and Grand Canonical Monte Carlo simulation study, J. Am. Chem. Soc., 128, 15300-15309, doi:10.1021/Ja065553, 2006.

Kaempfer, T. U., Schneebeli, M., and Sokratov, S. A.: A microstructural approach to model heat transfer in snow, Geophys. Res. Lett., 32, L21503, doi:10.1029/2005GL023873, 2005.

Kerbrat, M., Pinzer, B. R., Huthwelker, T., Gäggeler, H. W., Ammann, M., and Schneebeli, M.: Measuring the specific surface area of snow with X-ray tomography and gas adsorption: Comparison and implications for surface smoothness, Atmos. Chem. Phys., 8, 1261-1275, doi:10.5194/acp-8-1261-2008, 2008.

Kerbrat, M., Huthwelker, T., Gäggeler, H. W., and Ammann, M.: Interaction of nitrous acid with polycrystalline ice: Adsorption on the surface and diffusion into the bulk, J. Phys. Chem. C, 114, 2208-2219, doi:10.1021/jp909535c, 2010.

Knight, C. A.: Reply, J. Geophys. Res., 101, 12933-12936, doi:10.1029/96JD00556, 1996a.

Knight, C. A.: Surface layers on ice, J. Geophys. Res., 101, 1292112928, doi:10.1029/96JD00554, 1996b.

Kos, G. and Ariya, P. A.: Volatile organic compounds in snow in the Quebec-Windsor Corridor, J. Geophys. Res., 115, D01302, doi:10.1029/2009JD012391, 2010.

Krepelova, A., Bartels-Rausch, T., Brown, M. A., Bluhm, H., and Ammann, M.: Adsorption of acetic acid on ice studied by ambient-pressure XPS and partial-electron-yield NEXAFS spectroscopy at 230-240 K, J. Phys. Chem. A, 117, 401-409, doi:10.1021/jp3102332, 2013.

Li, Y. and Somorjai, G. A.: Surface premelting of ice, J. Phys. Chem. C, 111, 9631-9637, 2007.

Löwe, H., Spiegel, J., and Schneebeli, M.: Interfacial and structural relaxations of snow under isothermal conditions, J. Glaciol., 57, 499-510, doi:doi:10.3189/002214311796905569, 2011.

Marinelli, F. and Allouche, A.: An ab initio study of acetone and formaldehyde monolayers adsorbed on ice, Chem. Phys., 272, 137-147, doi:10.1016/S0301-0104(01)00442-6, 2001.

McNeill, V. F., Loerting, T., Geiger, F. M., Trout, B. L., and Molina, M. J.: Hydrogen chloride-induced surface disordering on ice, $P$. Natl Acad. Sci., 103, 9422-9427, doi:10.1073/pnas.0603494103, 2006.

McNeill, V. F., Geiger, F. M., Loerting, T., Trout, B. L., Molina, L. T., and Molina, M. J.: Interaction of hydrogen chloride with ice surfaces: The effects of grain size, surface roughness, and surface disorder, J. Phys. Chem. A, 111, 6274-6284, doi:10.1021/Jp068914g, 2007.

Neu, J. L. and Prather, M. J.: Toward a more physical representation of precipitation scavenging in global chemistry models: Cloud overlap and ice physics and their impact on tropospheric ozone, Atmos. Chem. Phys., 12, 3289-3310, doi:10.5194/acp-12-32892012, 2012.

Peybernès, N., Marchand, C., Le Calvé, S., and Mirabel, P.: Adsorption studies of acetone and 2,3-butanedione on ice surfaces between 193 and 223 K, Phys. Chem. Chem. Phys., 6, $1277-$ 1284, doi:10.1039/B315064j, 2004.

Picaud, S. and Hoang, P. N. M.: Adsorption of acetone molecules on proton ordered ice. A molecular dynamics study, J. Chem. Phys., 112, 9898-9908, doi:10.1063/1.481627, 2000.

Pinzer, B. R. and Schneebeli, M.: Breeding snow: An instrumented sample holder for simultaneous tomographic and thermal studies, Meas. Sci. Technol., 20, 095705, doi:10.1088/09570233/20/9/095705, 2009.

Pinzer, B. R., Kerbrat, M., Huthwelker, T., Gäggeler, H. W., Schneebeli, M., and Ammann, M.: Diffusion of $\mathrm{NO}_{\mathrm{x}}$ and $\mathrm{HONO}$ in snow: A laboratory study, J. Geophys. Res., 115, D03304, doi:10.1029/2009JD012459, 2010.

Riche, F., Bartels-Rausch, T., Schreiber, S., Ammann, M., and Schneebeli, M.: Temporal evolution of surface and grain boundary area in artificial ice beads and implications for snow chemistry, J. Glaciol., 58, 815-817, doi:10.3189/2012JoG12J058, 2012a.

Riche, F., Schneebeli, M., and Tschanz, S. A.: Design-based stereology to quantify structural properties of artificial and natural snow using thin sections, Cold Reg. Sci. Technol., 79-80, 6774, doi:10.1016/j.coldregions.2012.03.008, 2012b.

Schwander, J., Barnola, J.-M., Andrié, C., Leuenberger, M., Ludin, A., Raynaud, D., and Stauffer, B.: The age of the air in the firn and the ice at Summit, Greenland, J. Geophys. Res., 98, 28312838, doi:10.1029/92JD02383, 1993.

Schwarzenbach, R. P., Gschwend, P. M., and Imboden, D. M.: Environmental organic chemistry, Wiley-Interscience, New York, 2003.

Seok, B., Helmig, D., Williams, M. W., Liptzin, D., Chowanski, K., and Hueber, J.: An automated system for continuous measurements of trace gas fluxes through snow: An evaluation of the gas diffusion method at a subalpine forest site, Niwot Ridge, Colorado, Biogeochem., 95, 95-113, doi:10.1007/s10533-0099302-3, 2009.

Shepson, P. B. and Sumner, A. L.: Snowpack production of formaldehyde and its effect on the Arctic troposphere., Nature, 398, 230-233, doi:10.1038/18423, 1999.

Snider, J. R. and Dawson, G. A.: Tropospheric light alcohols, carbonyls, and acetonitrile: Concentrations in the southwestern United States and Henry's Law data, Journal of Geophysical Research: Atmospheres, 90, 3797-3805, doi:10.1029/JD090iD02p03797, 1985.

Starr, D. E., Pan, D., Newberg, J. T., Ammann, M., Wang, E. G., Michaelides, A., and Bluhm, H.: Acetone adsorption on ice investigated by X-ray spectroscopy and density functional theory, Phys. Chem. Chem. Phys., 13, 19988-19996, doi:10.1039/c1cp21493d, 2011. 
Swanson, A. L.: Trace gas emissions through a winter snowpack in the subalpine ecosystem at Niwot Ridge, Colorado, Geophys. Res. Lett., 32, L03805, doi:10.1029/2004GL021809, 2005.

Thibert, E. and Domine, F.: Thermodynamics and kinetics of the solid solution of $\mathrm{HCl}$ in ice, J. Phys. Chem. B, 101, 3554-3565, doi:10.1021/jp962115o, 1997.

Thomas, J. L., Stutz, J., Lefer, B., Huey, L. G., Toyota, K., Dibb, J. E., and von Glasow, R.: Modeling chemistry in and above snow at Summit, Greenland - part 1: Model description and results, Atmos. Chem. Phys., 11, 4899-4914, doi:10.5194/acp-11-48992011, 2011.

Ulrich, T., Ammann, M., Leutwyler, S., and Bartels-Rausch, T.: The adsorption of peroxynitric acid on ice between $230 \mathrm{~K}$ and $253 \mathrm{~K}$, Atmos. Chem. Phys., 12, 1833-1845, doi:10.5194/acp-12-18332012, 2012.
Winkelmann, J.: Diffusion of methanol; nitrogen, Vol. 15A, Springer-Verlag Berlin Heidelberg, doi:10.1007/978-3-54049718-9_538, 2007a.

Winkelmann, J.: Diffusion of propan-2-one; air, Vol. 15A, SpringerVerlag Berlin Heidelberg, doi:10.1007/978-3-540-49718-9_636, 2007b.

Winkler, A. K., Holmes, N. S., and Crowley, J. N.: Interaction of methanol, acetone and formaldehyde with ice surfaces between 198 and 223 K, Phys. Chem. Chem. Phys., 4, 5270-5275, doi:10.1039/B206258e, 2002. 